\title{
Comparison of PID and Fuzzy PID Controller for a Linearised Magnetic Bearing
}

\author{
T.K. Psonisa, E.D. Mitronikasa, P.G. Nikolakopoulos ${ }^{b}$ \\ a Department of Electrical and Computer Engineering in the University of Patras Rio, Patras, Greece, \\ b Department of Mechanical Engineering and Aeronautics in the University of Patras Rio, Patras, Greece.
}

Keywords:

Circuit stability

Fuzzy control

Fuzzy logic

Linear model

Magnetic bearings

PID control

Corresponding author:

Pantelis G. Nikolakopoulos

Department of Mechanical Engineering

and Aeronautics in the University of

Patras Rio, Patras, Greece.

E-mail: pnikolakop@upatras.gr

\begin{abstract}
A B S T R A C T
This paper is a presentation of a linear model of a magnetic bearing and a comparison of two controllers concerning their control performance. Initially, the benefits obtained by the use of magnetic bearings in the electromechanical systems are presented. Afterwards, the necessity for a suitable controller design is discussed in terms of the instability of the open loop system. Looking for a suitable control manner, a controller that behaves non-linearly, such as a fuzzy PID controller has been chosen in this paper. The use of such a non-linear controller improves both the results and the range of its use of the above system. The linear and the Fuzzy PID controller are compared using extensively simulation tests with the existence of white noise signal. The results of these comparisons, concerning the stability of these controllers are discussed and presented.
\end{abstract}

(C) 2017 Published by Faculty of Engineering

\section{INTRODUCTION}

The use of magnetic levitation in motor bearings is a relative new idea which has been widely investigated through the last years. This idea seems to have many advantages over the conventional technology of existing bearings, like ball or oil bearings. The main advantage is that, due to levitation, the rotor and the bearing don't have any friction between them. This means that the motor has lower maintenance costs and longer life of the shaft. An additional factor contributing to the cost is the elimination of the lubrication seals. This elimination gives the potential for redefinition of rotor's dimensions and limits of strength. As lack of friction means absence of additional vibrations caused by it and the maximum rotation speed of the shaft can be also increased. In addition, the non-contact between the rotor and the bearing and the absence of lubrication make these new bearings ideally suitable for use in a variety of vacuum applications and sterile clean rooms. These advantages have been the subject of research work in a wide range of studies of magnetic bearings [1-4]. The above studies have shown the need for the use of linear controllers, in order to control the behaviour of the magnetic bearings [5]. The need for better results in conjunction with the limited abilities of linear controllers, lead the studies to create more complex models. Farmakopoulos et al. [6] 
presented PID models regarding the linear Active Magnetic Bearing and a Hydromagnetic Bearing. They also presented the stability limits of the proposed controllers.

Furthermore, a non-linear controller for magnetic bearings control which was tested on a linearized system reportedly offers many advantages. In ref. [7] it is referred by the authors, that the use of Fuzzy as a controller, the system could have some advantages like shorter tuning time, accelerated response and reduced overshoot. All the above resulted to more robust systems and improved their dynamic and static performances. Other works studied exclusively the fuzzy controller and present classifications based by inputs of fuzzy [8], or compare the fuzzy controllers to a specific system [9]. In [9] the basic design principle of a fuzzy PID controller and the comparison with a regular PID is presented. These two controllers have been simultaneously tested using the same linearized active magnetic bearing (AMB) model which is excited by external disturbances. The system of an AMB and the classical PID controller has been analytically presented in [10].

\section{METHODOLOGY}

\subsection{Models and Formulations}

The system that is being studied here, represents a structure of an AMB which has one degree of freedom. It consists of a pair of electromagnets and a cylindrical mass of iron which corresponds to the rotor of the machine (Fig. 1). This mass has diameter $5 \mathrm{~cm}$ and length $5 \mathrm{~cm}$. It is assumed that the mass density of the shaft is $7.9 \mathrm{~g} / \mathrm{cm} 3$ for the sake of convenience calculations. The number of turns are 50 for each pole and the gap between the rotor and the inner wall of the bearing set is $0.5 \mathrm{~mm}$ [5,11-13].

The actual system of the magnetic bearing contains non-linearities due to the use of nonideal coils, electromagnetic forces and due to the air gap. For linearizing the above system, the following assumptions have been made: the rotor is rigid and symmetric, gyroscopic effects is neglected, leakage of magnetic flux is neglected, the magnetic iron is operating below the saturation level, unbalance in the rotor is purely static, rotor motion in the axial direction is neglected and the flux leakage in the air gap is neglected $[5,14]$.

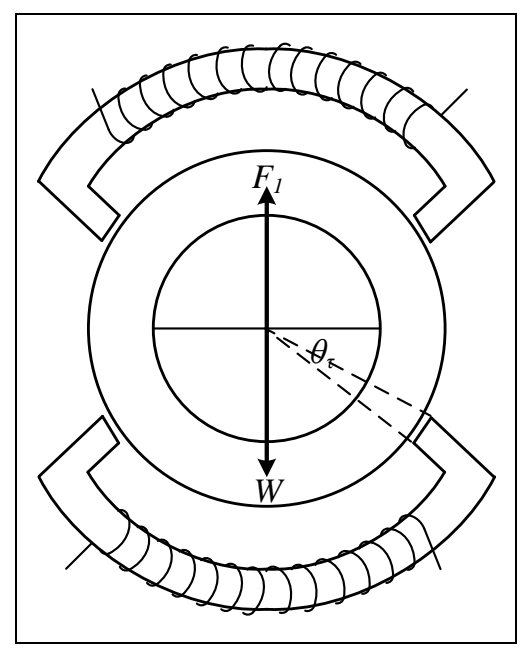

Fig. 1. A 1D magnetic bearing.

At the equilibrium point of the rotor, the weight (W) and the force that comes from the electromagnet (F1) are acted in the system, as described in the following equations (1-3):

$$
\boldsymbol{F}_{1}-\boldsymbol{W}=0 \Rightarrow \boldsymbol{I}_{\text {bias }}=\sqrt{\frac{(\boldsymbol{W} \times 2 \times \boldsymbol{g})}{\left(\frac{\boldsymbol{N}^{2} \times \boldsymbol{\mu}_{0} \times \boldsymbol{S}}{2 \times \boldsymbol{g}}\right)}}
$$

$$
\begin{gathered}
\boldsymbol{S}=\boldsymbol{l} \times\left(\boldsymbol{\pi} \times \boldsymbol{D} \times \frac{\boldsymbol{\theta}_{\boldsymbol{t}}}{360}\right)=5.45 \times 10^{-4} \boldsymbol{m}^{2} \\
I_{\text {bias }}=4.91779 \mathrm{~A}
\end{gathered}
$$

The characteristic equation of the above magnetic bearing can be simply written as:

$$
\frac{\boldsymbol{k}_{i}}{\boldsymbol{m} \times \boldsymbol{s}^{2}-\boldsymbol{k}_{x}}
$$

The above characteristic equation represents a system which has no zeros and two poles, $S_{1,2}= \pm \sqrt{\frac{k_{x}}{m}}$.

The system is unstable as it has a positive pole. The stability of the system is achieved with the presence of an appropriate control of closed loop system.

At first, the system is designed to be controlled with a classic PID controller. The gains of the controller have been selected in our previous paper [10], where the stability of the system, the speed of the controller and the system response has been investigated. The gain values are as follows: Proportional Gain 1526.6269, Integral 
Gain 13330.5096 and Differential Gain 15.8724. The reference tracking of the PID controller is shown in Fig. 2.

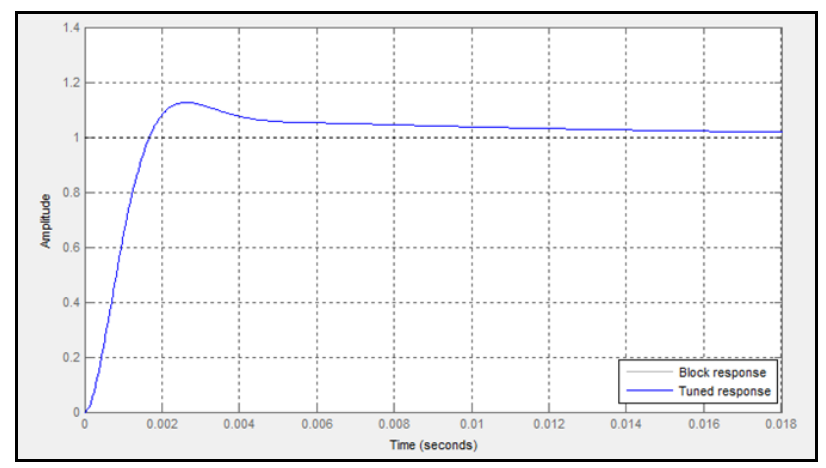

Fig. 2. Reference tracking for PID controller.

In Fig. 3, the block diagram of the system and the noise existence is also presented. This noise signal is white noise which has been added to the system in order to simulate the external disturbances which can adversely affect the system. The position where the noise has been added into the system is not accidental, and it is described by an individual block. Also, the transfer function of magnetic bearing is the transfer function of a linearized system in which the previous assumptions [5,14] are valid. Therefore, the linearized system which is described by the transfer function of Fig. 3 is a system which can be considered isolated from external disturbances.

The determination of the type and the value of the external disturbances were based on [6], which represents the operation of a magnetic bearing, which in its turn accepts external disturbances to the down force of the machine's shaft. The white noise has been selected, as it is an ideal form of noise, which is independent of the frequency variations. The spectrum of the white noise has the same constant value for all the range of the frequencies [15]. This interference of noise causes disturbances in the system which the PID controller seeks to cancel. As the noise isn't a constant value, it would be desirable to redefine the controller gains based on noise values in each cycle of the closed-loop system. This ability is being provided to the system by the Fuzzy controller. This controller is based on a knowledge representation method and a fuzzy logic decisionmaking mechanism. This knowledge is introduced to the controller by the fuzzy rules. For the determination of the rules, it's necessary to understand the influence of the controller gains to the response of the system. The theoretical data regarding this influence are shown in Table 1. For obtaining quantitative knowledge some trials were made via simulations, and the results are shown in the Table 2.

Table 1. Effect of controllers in the system.

\begin{tabular}{|c|c|c|c|c|}
\hline Controller & $\begin{array}{c}\text { Raising } \\
\text { time }\end{array}$ & Raising & $\begin{array}{c}\text { Restoration } \\
\text { time }\end{array}$ & $\begin{array}{c}\text { Permanent } \\
\text { error }\end{array}$ \\
\hline Proportional & Reduction & Increase & $\begin{array}{c}\text { Minor } \\
\text { change }\end{array}$ & Reduction \\
\hline Integral & Reduction & Increase & Increase & Elimination \\
\hline Derivative & $\begin{array}{c}\text { Minor } \\
\text { change }\end{array}$ & Reduction & Reduction & $\begin{array}{c}\text { Minor } \\
\text { change }\end{array}$ \\
\hline
\end{tabular}

Table 2. Test data for the gains effect in the system.

\begin{tabular}{|c|c|c|c|c|}
\hline & $\begin{array}{c}\text { Raising } \\
\text { time }\end{array}$ & Raising & $\begin{array}{c}\text { Restoration } \\
\text { time }\end{array}$ & $\begin{array}{c}\text { Permanent } \\
\text { error }\end{array}$ \\
\hline \multicolumn{5}{|c|}{ Kp (initial value 1526.6269) } \\
\hline 1200 & Reduction & Reduction & Indifferent & Increase \\
\hline 1600 & Reduction & Increase & Indifferent & Reduction \\
\hline 1800 & Increase & Increase & Reduction & Reduction \\
\hline 2000 & Increase & Increase & Reduction & Reduction \\
\hline 3000 & Increase & Increase & Reduction & Reduction \\
\hline \multicolumn{6}{|c|}{ Ki (initial value 13330.5096) } \\
\hline 10000 & Indifferent & Reduction & Indifferent & Increase \\
\hline 15000 & Indifferent & Increase & Indifferent & Reduction \\
\hline 18000 & Indifferent & Increase & Indifferent & Reduction \\
\hline 23000 & Indifferent & Increase & Indifferent & Reduction \\
\hline 32000 & Indifferent & Increase & Indifferent & Reduction \\
\hline \multicolumn{6}{|c|}{ Kd (initial value 15.8724) } \\
\hline 10 & Increase & Increase & Increase & Indifferent \\
\hline 18 & Reduction & Reduction & Reduction & Indifferent \\
\hline 22 & Reduction & Reduction & Reduction & Indifferent \\
\hline 30 & Reduction & Increase & Increase & Indifferent \\
\hline
\end{tabular}

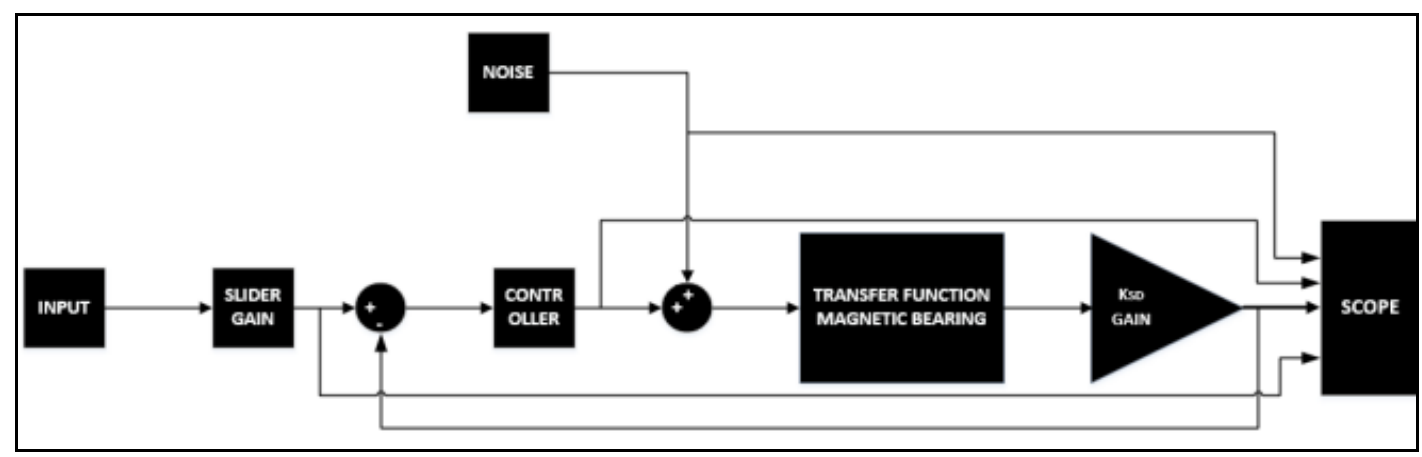

Fig. 3. Block Diagram of the system with PID controller. 
The fuzzy PID controller (Fig. 4) has two inputs, the rotor position error and the derivative of it, and three outputs which are the three gains of the PID controller. The small range of the position error (Fig. 5) in combination with the derivative of it makes the controller more sensitive even in small disturbances and helps it discriminate between temporary and permanent errors.

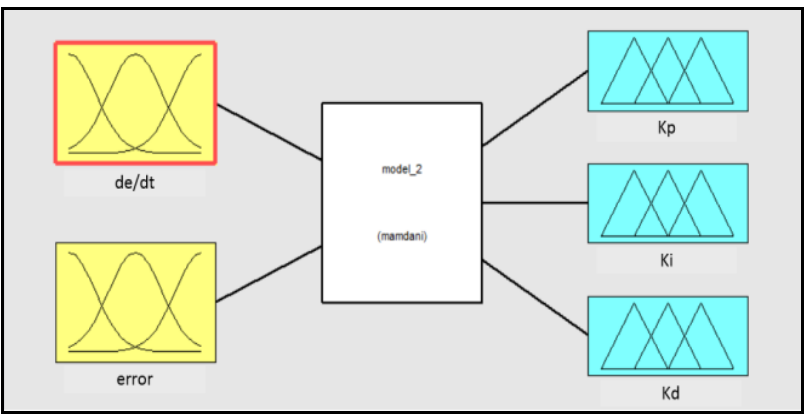

Fig. 4. Structure of the fuzzy controller.

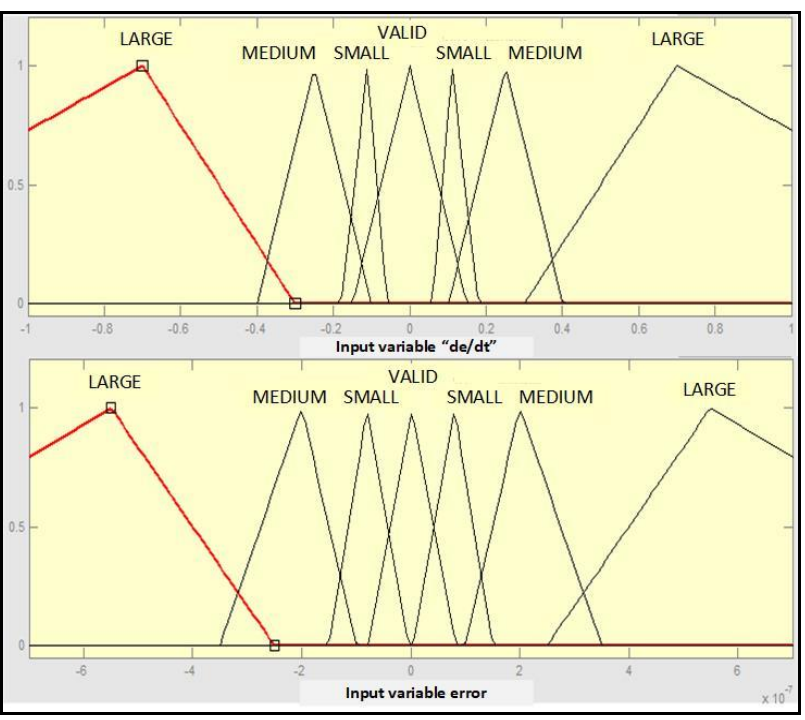

Fig. 3. Input membership functions of the fuzzy controller.

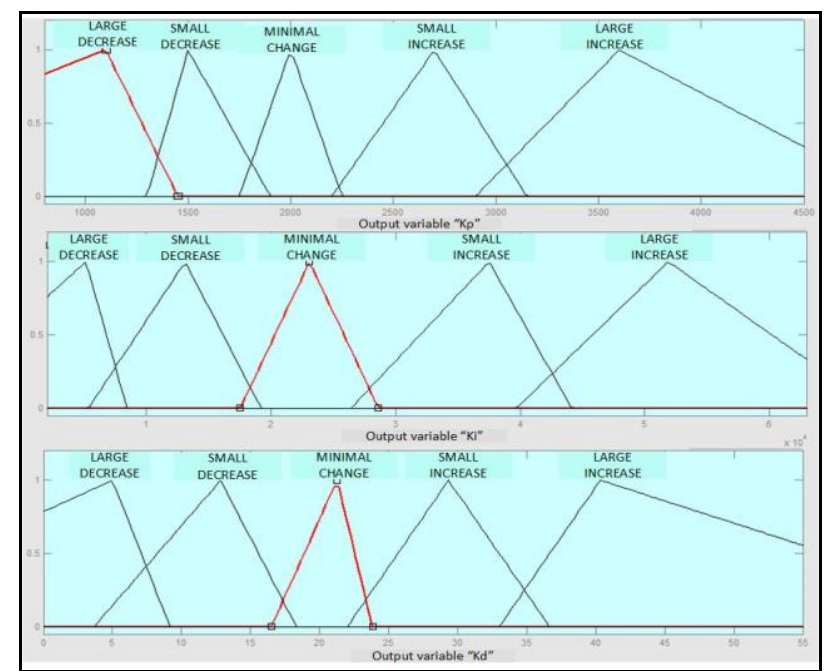

Fig. 4. Output membership functions of the fuzzy controller.

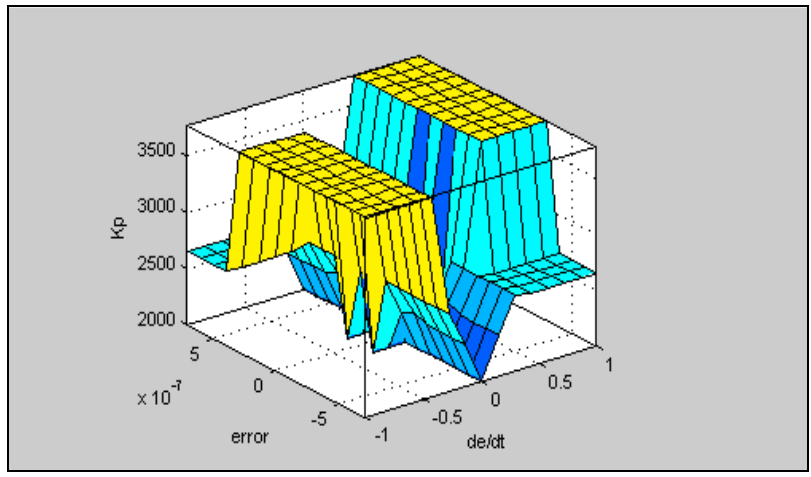

Fig. 5. The output surface of Kp.

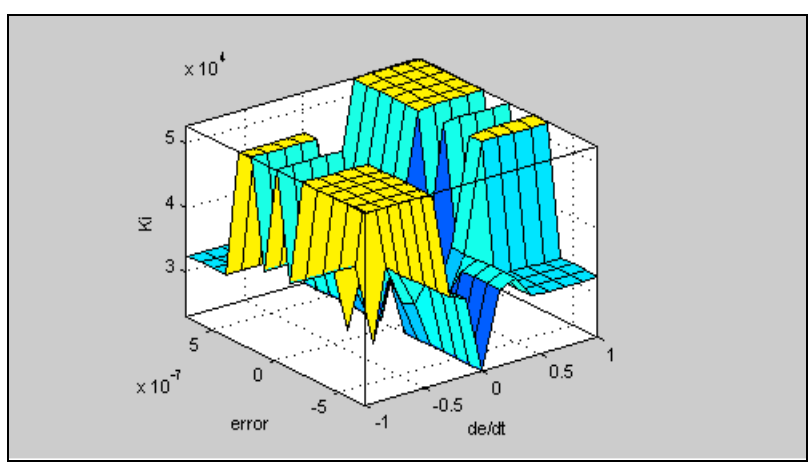

Fig. 6. The output surface of Ki.

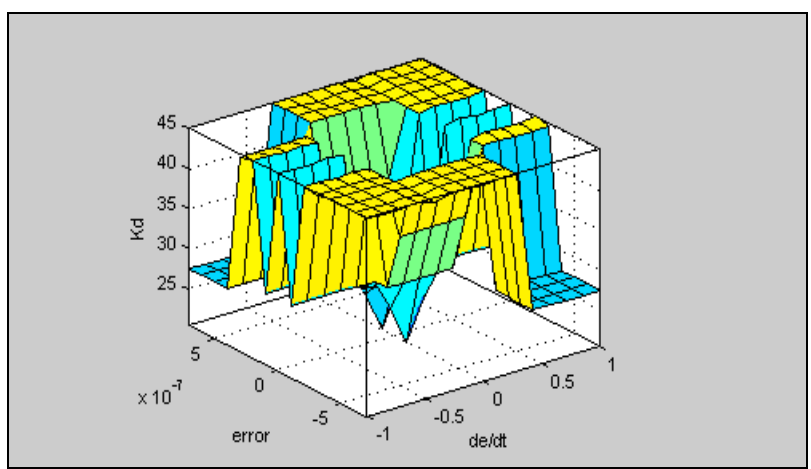

Fig. 7. The output surface of Kd.

The variation of the PID's gains, which are the outputs of fuzzy controller (Figs. 6-9), is determined by certain rules, which are set after the evaluation of the above theoretical and experimental data on the influence of gains [15]. In Fig. 10 the block diagram of the system with the fuzzy PID controller is presented.

\subsection{Simulation results with Fuzzy and a classic PID Controller}

The system with the simple PID controller (Fig. 3 ) has the following time-unchanged transfer function as the controller's gains are fixed. 


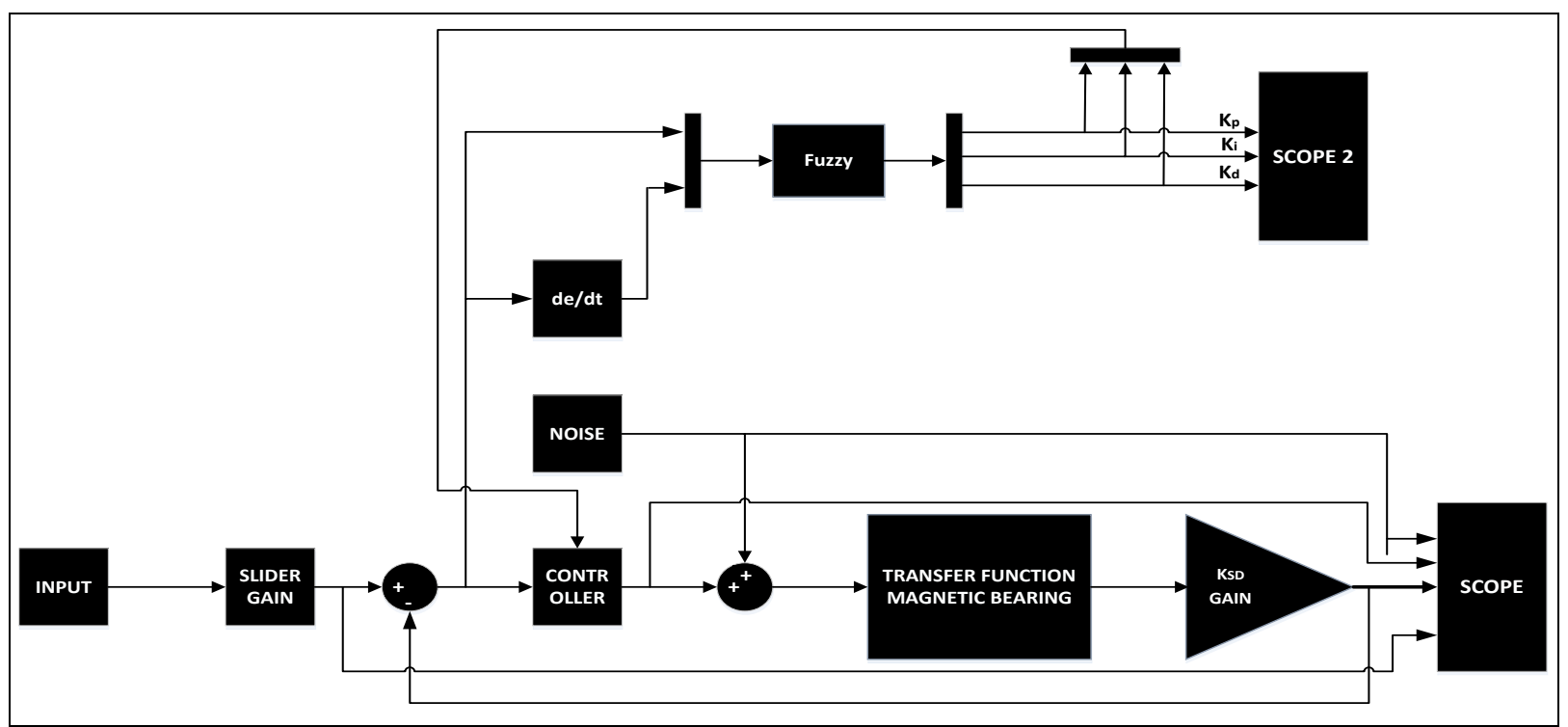

Fig. 10. Block Diagram of the system with fuzzy PID controller.

$$
\frac{X}{X^{\prime}}=\frac{\left[s^{2}\left(K_{p}+N \times K_{d}\right)+s\left(K_{p} \times N+K_{i}\right)+K_{i} \times N\right] \times k_{i} \times k_{s n}}{m \times s^{4}+N \times m \times s^{3}+\left(\left(K_{p}+N \times K_{d}\right) \times k_{i} \times k_{s n}-k_{x}\right) s^{2}+\left(\left(K_{p} \times N+K_{i}\right) \times k_{i} \times k_{s n}-k_{x} \times N\right) \times s+k_{i} \times K_{i} \times N \times k_{s n}}
$$

The poles of the above function are:

$\mathrm{P} 1=-9.71450, \mathrm{P} 2=-90.13387$

$P 3=-1128.92409+1177.08749 * i$,

$\mathrm{P} 4=-1128.92409-1177.08749 *_{\mathrm{i}}$

The stability of the system derives from the fact that all the poles have a negative real part, which means that they reside in the left half-plane.

The system with fuzzy PID controller has a timechanging transfer function as the gain of controller changes in each cycle of the system. The variation of the gains, (outputs of the fuzzy controller), is made through the fuzzy rules so that the system remains stable, having all poles in the left (negative), half-plane.

The analysis of the above diagrams (Figs. 1118) leads to important conclusions. First, the similarity of the controller's output is obvious. However the fuzzy controller leads to a more effective PID control. Furthermore, as the fuzzy leads to a better PID, it is evident that it has better response than the classic PID (Figs. $11,13,15)$. The main conclusions derived by the diagrams are the following two: Firstly, the system with the fuzzy controller is stable as the position of the rotor and the current of the controller remains within the permissible limits.

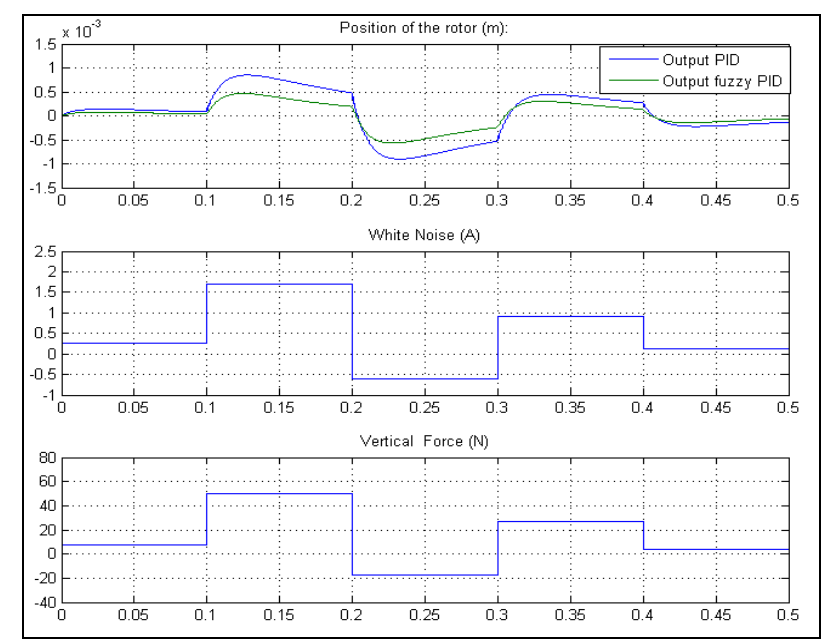

Fig. 8. Plot of PID and fuzzy PID outputs for a noise power of 0.05 .

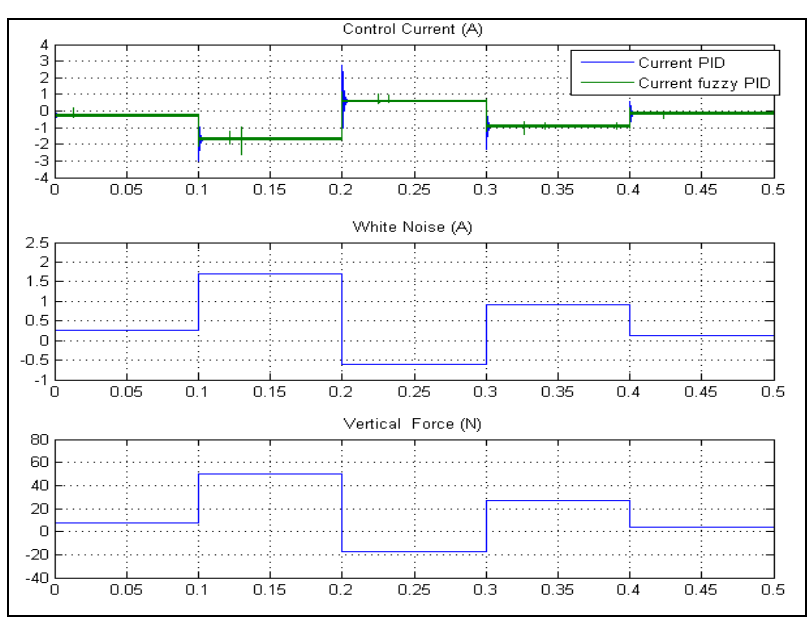

Fig. 12. Plot of PID and fuzzy PID control currents for a noise power of 0.05 . 


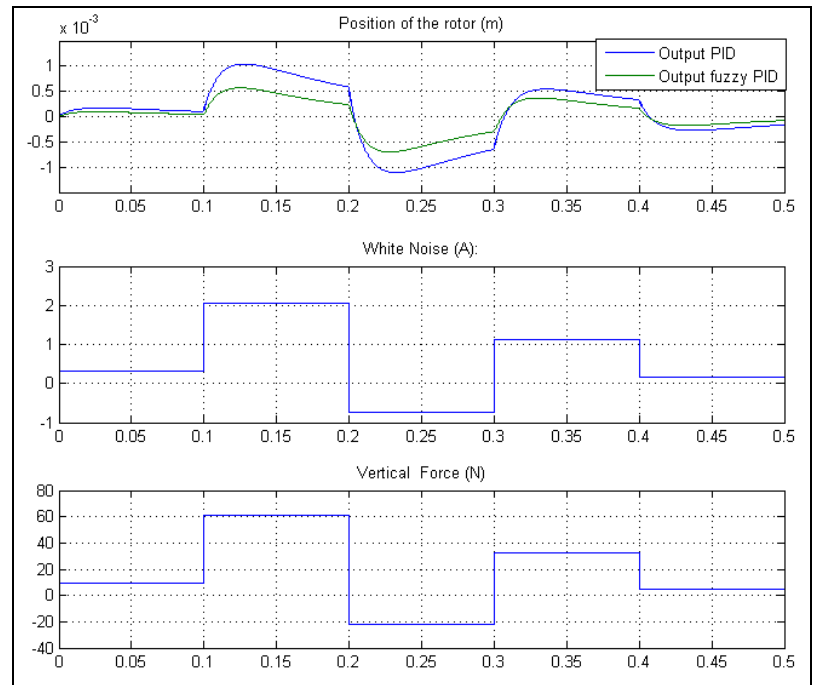

Fig. 9. Plot of PID and fuzzy PID outputs for a noise power of 0.075 .

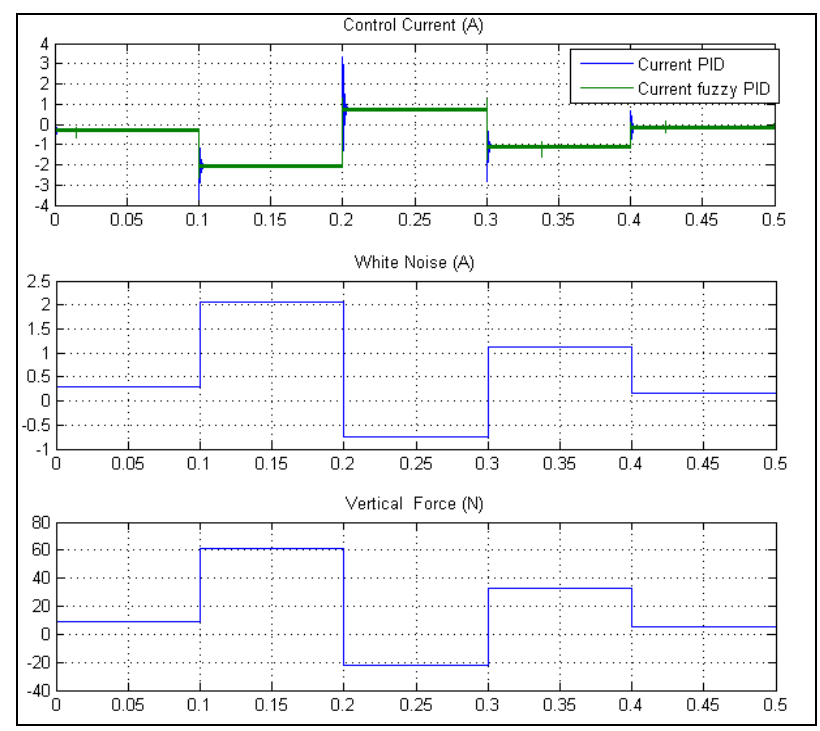

Fig. 14. Plot of PID and fuzzy PID control currents for a noise power of 0.075 .

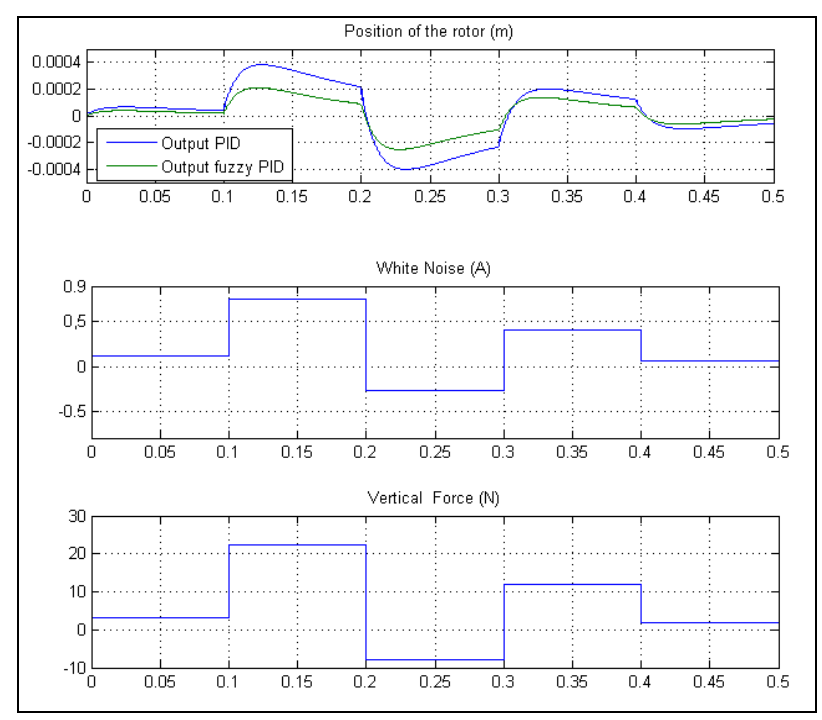

Fig. 15. Plot of PID and fuzzy PID outputs for a noise power of 0.01 .

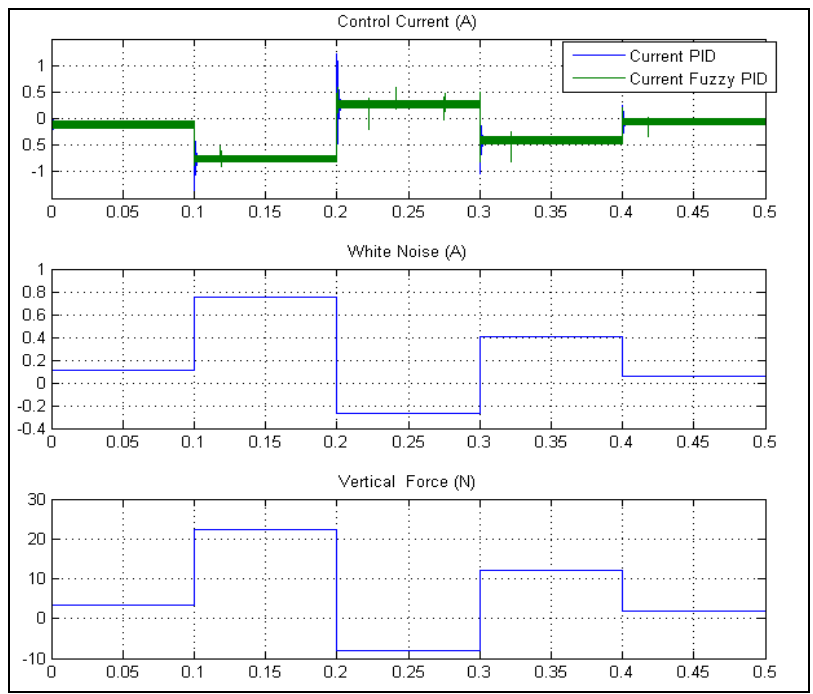

Fig. 16. Plot of PID and fuzzy PID control currents for a noise power of 0.01 .

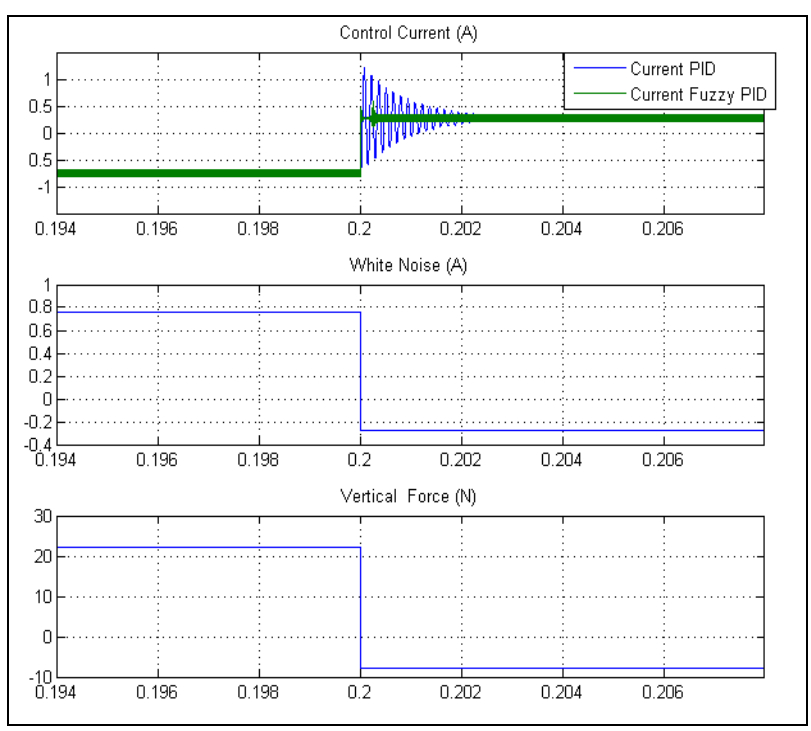

Fig. 17. Plot of PID and fuzzy PID control currents for a noise power of 0.01 (detail view).

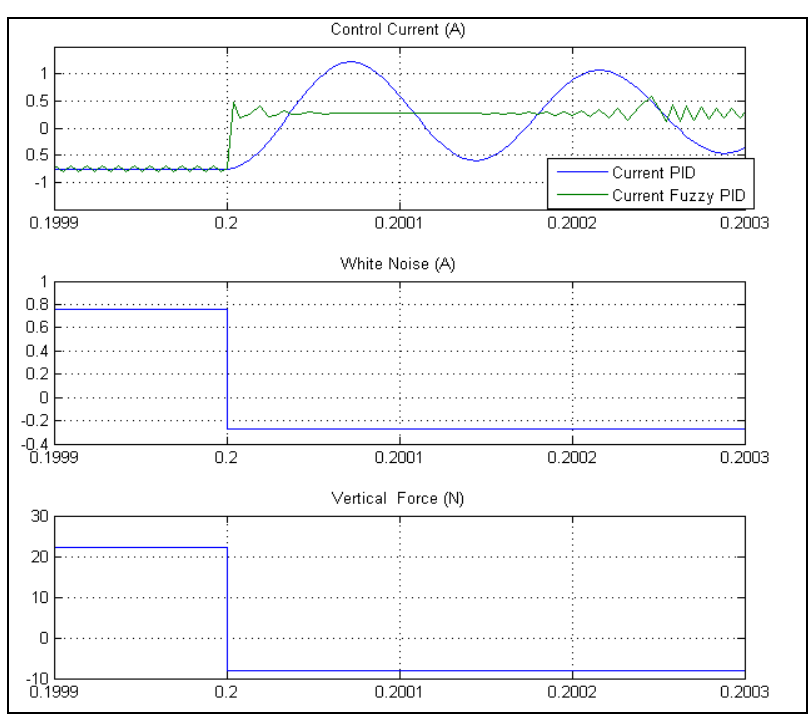

Fig. 18. Plot of PID and fuzzy PID control currents for a noise power of 0.01 (detail view). 
This had also been secured from the study and the determination of the fuzzy controller rules. Secondly, (Figs.12,14,16-18), the control current of fuzzy is less than the control current of PID controller. This means, that the overall electrical efficiency of the bearing can be maximized.

\section{CONCLUSION}

In this paper a comparison between two different controllers for an active magnetic bearing is presented. This comparison shows the advantages of fuzzy PID controller than the classic PID concerning both the response of the system and the energy needed to supply the control system. The fuzzy controller supplies in each cycle of the control new PID gains. This process results to a stable system with an optimum PID controller. Finally, the two controllers has been simulated in the same time with a white noise signal, which represents external disturbances. The long term objective is the creation of a fuzzy control system for the real motor. The investigation is still under process and the controller may be improved by adding new rules and use new forms of input and output fuzzy membership functions.

\section{REFERENCES}

[1] G. Schweitzer and E.H. Maslen. "Magnetic Bearings Theory, Design and Application to Rotating Machinery". Berlin: Springer, 2009.

[2] S.-L. Chen, S.-Y. Hsu, P.-L. Wang and D. Jaung, "A feasibility Study of Bearingless Motor Based on Three-Pole Active Magnetic Bearing", International Journal of Automation and Smart Technology, vol. 2, no. 2, pp. 1-8, 2012.

[3] L. Dong and S. You, "Adaptive control of an active magnetic bearing with external disturbance", ISA Transaction, vol. 53, no. 5, pp. 1410-1419, 2014.

[4] A. Chiba, T. Fukao and O. Ichikawa. "Magnetic Bearings and Bearingless Drives". Amsterdam: Elsevier, 2005.

[5] D. Polajžer, J. Ritonja, G. Ŝtumberger, D. Dolinar and J. Lecointe "Decentralized PI/PD position control for active magnetic bearings", Electrical Engineering (Archiv für Elektrotechnik), vol. 89, no. 1 , pp. $53-59,2006$.

[6] M.G. Farmakopoulos, E.K. Loghis, P.G. Nikolakopoulos, N.I. Xiros and C.A. Papadopoulos. "Modeling and Control of the
Electrical Actuation System of an Active Hydromagnetic Journal Bearing (AHJB)", Proceedings of the ASME 2014 International Mechanical Engineering Congress \& Exposition, Montreal, Quebec, Canada, 2014, pp. V04BT04A043,10 pages.

[7] S.-C. Chen, V.-S. Nguyen, D.-K. Le and T.-H.-N. Nguyen, "Nonlinear Control of an Active Magnetic Bearing System Achieved Using a Fuzzy Control with Radial Function Neural Network", Journal of Applied Mathematics, vol. 2014, Article ID 272391, 18 pages, 2014.

[8] B. Akbiyik, I. Eksin, M. Guzelkaya and E. Yesin, "Evaluation of the Performance of Various Fuzzy PID Controller Structures on Benchmark Systems", ELECO, 4rd International Conf. of Electrical and Electronics Engineering, Bursa, Turkey, 2005, pp. 388-393.

[9] E. Yeşil, M. Güzelkaya and İ. Eksin, "Fuzzy PID controllers: An overview", The Third Triennial ETI International Conference on Applied Automatic Systems, Ohrid, Macedonia, 2003, vol. 1, pp. 105-112.

[10] T. Psonis, P. Nikolakopoulos and E.D. Mitronikas, "Design of a PID controller for a linearised Magnetic Bearing", International Journal of Rotating Machinery, vol. 2015, Article ID 656749, 12 pages, 2015.

[11] W. de Boer. Active Magnetic Bearings: "Modelling and control of a five degrees of freedom rotor", M.Sc. Thesis, Eindhoven University of Technology, 1998.

[12] G. Schweitzer. "Active magnetic bearings-chances and Limitations", Proc. 6th Internat. IFToMM Conf. on Rotor Dynamics, Sydney, 2002, pp. 1-14.

[13] B. Polajžer, D. Dolinar, G. Štumberger, J. Ritonja, B. Grčar and K. Hameyer, "Design of Horizontal Shaft Active Magnetic Bearing System", 2nd International seminar on Vibrations and acoustic noise of electric machinery, Lodz, Poland, 2012, pp. 51-55.

[14] M.K. Habib and J. Inayat-Hussain, "Fuzzy Logic Based Control of Rotor Motion in Active Magnetic Bearings", Cybernetics and Intelligent System, IEEE, vol. 2, pp. 1219-1225, 2004.

[15] T. Psonis, E.D. Mitronikas and P. Nikolakopoulos, "A fuzzy control model for bearingless motors", in Proceeding of the ICEAF IV, International Conference of Engineering Against Failure, Skiathos, Greece, 2015, pp. 286-297.

\section{Nomenclature}

$F_{1}$ : Force from electromagnet.

$g: \quad$ The gap between the rotor and the inner wall of the bearing 
T.K. Psonis et al., Tribology in Industry Vol. 39, No. 3 (2017) 349-356

Ibias: Current bias.

$K_{D}$ : Derivative Gain

$K_{I}: \quad$ Integral Gain

Ki: $\quad$ Force-Current factor

$K_{P}$ : Proportional Gain

$k_{s n}: \quad$ Sensor Gain

$k_{x}$ : $\quad$ Force-Displacement factor (stiffness coefficients)

l: $\quad$ Stack length. $m: \quad$ mass of shaft

$N$ : Number of turns

PID: Proportional Integral Derivative

$S$ : Cross-section area of flux path.

$W$ : Weight of shaft

$\theta_{t}$ : $\quad$ Angle between shaft and electromagnet. $\theta_{t}=25 \mathrm{deg}$

$\mu_{0}: \quad$ Permeability of free space. 